\title{
A GeRMinAÇÃo dO EMPREENDEDOR DO BRASIL CONTEMPORÂNEO: O NEOLIBERALISMO VISTO SOB O CONTEXTO NACIONAL RECENTE
}

\author{
Claudio Luis de Camargo PENTEADO* \\ Brauner Geraldo CRUZ JUNIOR ${ }^{* *}$
}

\begin{abstract}
RESUMO: O artigo apresenta uma discussão sobre o desenvolvimento de um tipo específico de empreendedor na sociedade brasileira contemporânea. Os avanços sociais e econômicos dos governos lulistas possibilitaram um crescimento da renda de parte significativa da população brasileira que, ao adquirir novos modos de vida, viu também suas referências culturais serem transformadas. Em especial, a figura do empreendedor tornou-se representativa da nova realidade brasileira. No contexto de uma sociedade neoliberal, onde as empresas de si mesmo e a norma da concorrência se propõem universais, a acepção do simbolismo empreendedor se fez ainda mais latente. Contudo, observou-se no Brasil contemporâneo um tipo de empreendedor distinto daquele retratado pelo discurso neoliberal. Para mostrar essas diferenças, oito trajetórias de empreendedores populares brasileiros foram mobilizadas, e ao final, importantes ambiguidades e novas categorias de valores e ações puderam ser identificadas, configurando um empreendedor característico do Brasil recente.
\end{abstract}

PALAVRAS-CHAVE: Empreendedorismo. Neoliberalismo. Lulismo. Classes populares. Nova classe média brasileira

Introdução

O período compreendido entre os anos de 2003 e 2014 concentrou momentos de profundos avanços sociais e econômicos para a sociedade brasileira. A emergência

\footnotetext{
* UFABC - Universidade Federal do ABC. Programa de Pós-Graduação em Ciências Humanas e Sociais (PPGCHS). São Bernardo do Campo - SP - Brasil. 09606-045 -

claudio.penteado@ufabc.edu.br. https://orcid.org/0000-0002-8279-3643

** UFABC - Universidade Federal do ABC. Programa de Pós-Graduação em Ciências Humanas e Sociais (PPGCHS). São Bernardo do Campo - SP - Brasil. 09606-045 - brauner.cruz_jr@hotmail.com.

https://orcid.org/0000-0002-2105-5890
} 
de políticas sociais de combate à pobreza no governo Lula em 2003 e a continuação de boa parte de seu legado por Dilma Rousseff em 2011 provocaram um rearranjo na composição das classes sociais, sobretudo em termos de renda, ao oferecer melhores perspectivas de consumo, acesso a serviços e infraestrutura às camadas mais populares no Brasil. Dados do Instituto Econômico de Pesquisas Aplicadas (IPEA) relataram uma redução do Índice de Gini, que mede a desigualdade entre os cidadãos de cada país, de 0,583 para 0,518, de 2003 a 2014 (BRASIL, 2018); Kerstenetzky (2017) apontou para uma queda de $18 \%$ na pobreza absoluta nesse mesmo período; em 2010, o país atingiu 7,5\% de crescimento econômico, o maior índice em 24 anos (G1, 2011); ainda, um estudo de Guimarães (2012) para a Organização Internacional do Trabalho (OIT) relatou um aumento no emprego formal de 53,6\% entre 2003 e 2010. No campo da infraestrutura, a reestruturação ou criação de políticas públicas como o 'Programa Luz para Todos', '1 milhão de cisternas (P1MC)' e 'Minha Casa, Minha Vida' garantiram maior acesso da população a serviços básicos, enquanto medidas como o aumento real (acima da inflação) do salário mínimo, políticas de incentivo ao crédito e o Programa Bolsa Família (PBF) incrementaram a renda de boa parte da população, que passou a compor o mercado consumidor de forma mais substantiva. Independente do olhar político que apliquemos a esse processo, se mais otimista ou não com os rumos e a sustentabilidade dessas mudanças, é mister reconhecer que o crescimento econômico e social obtido impactou a dinâmica entre as classes, simbólica e culturalmente, e gerou uma espécie de euforia momentânea sobre as possibilidades do Brasil continuar entre os protagonistas mundiais nos avanços econômicos e no combate às desigualdades.

Devido a uma profunda crise política que atravessou o país a partir de 2013, em parte fruto de um desejo popular pela continuidade ou aprofundamento dos avanços socioeconômicos - como a demanda pela melhoria dos serviços públicos nas jornadas de 2013 refletiu -, essa euforia tão latente ao final da primeira década do século XXI deu lugar a um pessimismo generalizado, aprofundado por uma crise econômica que indicava limites e importantes barreiras às políticas até então empregadas pelas gestões petistas. $\mathrm{O}$ crescimento econômico e o combate à miséria, às desigualdades e ao desemprego se transformaram em uma estagnação econômica (CURY; SILVEIRA, 2017), um retorno a índices de pobreza antes superados (FARIZA; MONTES, 2019) e a um aumento da informalidade e dos postos precários de trabalho (RDA, 2019).

A saída de Dilma Rousseff por meio de uma articulação parlamentar para a ascensão de Michel Temer e de um programa politicamente oposto ao da petista (ainda que este fosse seu vice) aumentou o declínio socioeconômico e originou um país dividido politicamente, com poucos consensos firmados. A eleição de Jair Bolsonaro 
em 2018 refletiu esse cenário e decretou o declínio do legado lulista, aprofundando as divergências com a agenda de combate à pobreza e às desigualdades.

No entanto, as transformações culturais do período 2003-2014 tiveram uma capacidade de influenciar simbolicamente a sociedade brasileira de tal maneira que uma análise apenas do momento político e econômico não seria capaz de captar essas nuances. Afinal, a euforia econômica vivenciada impulsionou a imagem de um contingente populacional que "pedia passagem" na dinâmica social por ter seus padrões de consumo alterados, acessado novos espaços e posições na sociedade e encarado uma nova realidade profissional. O grupo que na opinião pública ficou conhecido como nova classe média passou a buscar a manutenção de seu patamar na sociedade, num contexto em que não apenas o cenário nacional sofria transformações, mas onde a própria conjuntura global já havia imposto certos limites e, de certa forma, condicionado o desenvolvimento desse grupo social. Dessa maneira, Singer (2018) apontou que os governos federais petistas - ou o que chamou de lulismo - optaram por deixar com que a ilusão meritocrática fosse estabelecida como justificativa para o crescimento econômico dessas camadas mais baixas da sociedade, simultaneamente a uma realidade global que coadunava com o empreendedorismo num capitalismo altamente financeirizado, que impulsiona a figura dos que trabalham "por conta própria". A própria opção de crescimento via políticas de incentivo ao consumo e de formalização de postos de trabalho a partir da regularização daqueles que trabalhavam informalmente ou "por conta" - na efetivação da figura do Microempreendedor Individual (MEI) - foi ao encontro dessas tendências, germinando certo tipo de empreendedor popular brasileiro.

O neoliberalismo como uma nova razão de mundo, que influencia não apenas políticas econômicas de Estados nacionais, mas busca o governo dos sujeitos e das instituições (DARDOT; LAVAL, 2016, FOUCAULT, 2008), difundiu no cenário global a imagem de um novo indivíduo: aquele que se auto organiza seguindo os moldes de uma organização empresarial e, por isso mesmo, tem como norma reguladora das relações sociais a concorrência (DARDOT ; LAVAL, 2016). Nesse horizonte, a perspectiva do empreendedorismo enquanto materialização dessa auto-organização empresarial foi assimilada por boa parte da classe trabalhadora, que presenciou: a desorientação e enfraquecimento dos setores sindicais; a precarização da condição salarial e aprofundamento das desigualdades de renda; e a retomada do controle da força de trabalho (BOLTANSKI e CHIAPELLO, 2009). Muitos sujeitos, assim, passaram a se ver, por essa condição "à deriva", como empresários de si próprios. O cenário se expandiu de tal forma que mesmo a chave analítica da informalidade perdeu seu lastro, 
esvaziando-se de completo sentido e cedendo terreno ao olhar sobre a empregabilidade fornecida pela ideia do empreendedorismo, como pontuou Machado (2002).

Este artigo busca aprofundar justamente as novas categorias que surgem a partir dessa difusão do empreendedorismo, tendo em vista o contexto brasileiro e como ele condicionou essa difusão. Assim, trataremos de entender o empreendedor germinado no Brasil recente, considerando-o como um sujeito influenciado pelo discurso neoliberal e também condicionado pelas políticas lulistas e as representações culturais que advieram da ascensão social das camadas mais populares. Acreditamos que se trata da análise de um sujeito político fundamental para a compressão da sociedade brasileira num futuro próximo. Também consideramos importante diferenciar as características desse empreendedor em comparação a definições clássicas sobre o empreendedorismo. Para isso, traremos a trajetória de oito pessoas das classes populares - que, seguindo algumas óticas, podem ser consideradas como pertencentes a essa camada socialmente emergente tida por muitos como uma nova classe média - que trabalham autonomamente e lidam diariamente com a gestão de seus pequenos negócios ${ }^{1}$. Seguindo a classificação hegemônica, são pequenos empreendedores e empreendedoras típicos desse período da sociedade brasileira, e que servirão como exemplos dessas particularidades em termos de pensamento, ações e valores. Com isso, queremos dar luz a esse ator social ainda pouco explorado no debate social brasileiro: um sujeito que não é uma mera empresa de si mesmo, e tampouco simboliza a simples permanência das características tradicionais da classe trabalhadora brasileira.

O artigo está dividido em quatro partes, para além desta breve introdução. Primeiramente, buscaremos dar um pouco mais de espaço para as representações e análises que advieram sobre o Brasil entre 2003 e 2014, com foco nas transformações entre as classes sociais. Com esse panorama montado, entraremos no debate sobre como a figura do empreendedor que foi fomentada durante esse período se insere numa temática global sobre o avanço do discurso empreendedor em meio à sociedade neoliberal. Em seguida, traremos como exemplos as trajetórias das oito pessoas entrevistadas, que podem ser vistas como empreendedoras e empreendedores típicos desse contexto, guardando as diferenças contextuais que possuem entre si. Lançaremos, então, a discussão sobre esse sujeito político e como ele reflete, num primeiro momento, um legado do Brasil recente e do contexto global e local de sociedade, e num segundo momento, como ele se diferencia do tipo ideal de empreendedor do neoliberalismo,

\footnotetext{
${ }^{1}$ As trajetórias exibidas são parte da Dissertação $A$ empresa de si mesmo: $A$ assimilação do discurso empreendedor pelas camadas populares brasileiras, de Cruz Junior (2019), e foram aqui resumidas, além de enfatizados alguns recortes teóricos e analíticos para o propósito deste artigo.
} 
admitindo contradições, ambiguidades e, inclusive, a possibilidade de se pensar em novas categorias.

\section{Os governos Lula e Dilma e suas transformações sociais e culturais}

Para entendermos de modo mais aprofundado como se deram as transformações socioculturais na sociedade brasileira durante, principalmente, as gestões de Lula e Dilma no governo federal, consideramos relevante trazer alguns autores que se debruçaram a sintetizar o caráter das políticas empregadas por esses governos e como elas impactaram a dinâmica social brasileira.

Uma primeira interpretação, que balizou o discurso de diversos veículos de comunicação e chegou a se tornar, de certo modo, hegemônica na opinião pública para explicar a euforia generalizada que se vivenciava até então, é a feita por Marcelo Neri (2011). Ele é um economista que esteve à frente do Instituto de Pesquisas Econômicas Aplicadas (IPEA) e foi também ministro da Secretaria de Assuntos Estratégicos da Presidência da República (SAE) durante os mandatos de Lula e Dilma. Sua tese é a de que a camada social em ascensão na primeira década do século XXI havia atingido novos patamares de consumo e de renda que permitiam uma nova mirada. Era a ascensão da nova classe média (um novo termo para a classe C), que se diferenciava, simbólica e materialmente, das classes mais baixas e das classes médias tradicionais. Como definiu o autor:

Nova classe média dá o sentido positivo e prospectivo daquele que realizou - e continua a realizar - o sonho de subir na vida. Aonde você vai chegar é mais importante do que de onde você veio ou onde está. Nova classe média não é definida pelo ter, mas pela dialética entre ser e estar olhando para a posse de ativos e para decisões de escolha entre o hoje e o amanhã. Mais do que assíduos frequentadores de templos de consumo, o que caracteriza a nova classe média brasileira é o lado do produtor. A nova classe média busca construir seu futuro em bases sólidas que sustentem o novo padrão adquirido. (NERI, 2011, p.18-19, grifo nosso).

Assim, tem-se um grupo social que passa a buscar sua manutenção de padrão, e, para isso, recusa a valorização do consumo, prezando por seu lado produtor. Há, então, um forte apelo de Neri (2011) ao discurso empreendedor, que é mobilizado mais concretamente pelas referências àqueles que são "por conta própria": 
A carteira de trabalho é o maior símbolo da classe $\mathrm{C}$ como ato consumado, e o concurso público é o seu platônico objeto de desejo. Os "por conta própria” são os outros protagonistas fundamentais do mercado de trabalho brasileiro da classe $\mathrm{C}$, mas da classe E também. Verdadeiros capitalistas sem capital. E sem políticas públicas de apoio também como a do crédito produtivo popular (NERI, 2011, p.168).

O excerto acima representa certa dualidade que acompanha a descrição de Neri (2011) sobre as transformações socioeconômicas do Brasil recente. A nova classe média vista por sua ótica possui, ao mesmo tempo, um espírito aventureiro, na medida em que floresce seu lado empreendedor, mas ao buscar manter seu patamar de vida, flerta também com a segurança propiciada por trabalhos formais, representados pelos concursos públicos e pela carteira de trabalho.

Ainda que, segundo o economista, o empreendedorismo não fosse um componente incentivado pelo Estado brasileiro ("Estado, Empreendedorismo, Educação e Elite ainda são classe E aqui" (NERI, 2011, p.167)), sua análise foi amplamente adotada pelos governos lulistas. Sob sua gestão à frente da SAE, foram criados os Cadernos Vozes da Nova Classe Média, que, dentre outros elementos, acentuavam a importância do empreendedorismo como impulsionador desse grupo social. E podemos dizer que seu diagnóstico também foi amplamente adotado por institutos de pesquisa, que visavam entender o comportamento sociocultural e econômico da nova classe média, principalmente com fins de adequação ao mercado, assim como veículos de imprensa passaram a fazer reportagens e noticiar comportamentos dessa nova classe média.

A leitura de Marcelo Neri (2014) não foi unânime dentro das ciências sociais e da própria economia. A ideia de um grupo que se aproximava da classe média em termos de renda e consumo, ainda que preservasse certa singularidade, foi rechaçada, por exemplo, por Pochmann (2014). Para esse (também) economista, as políticas empregadas pelas gestões petistas tinham, na verdade, fortalecido as bases de uma classe trabalhadora, reduzindo, assim, uma perspectiva mais favorável à expansão do empreendedorismo.

Numa outra linha, Ruy Braga (2012) também discorda da leitura de que houve uma expansão das camadas médias no Brasil recente, mas tampouco acredita num fortalecimento da classe trabalhadora. O que este sociólogo chama de hegemonia lulista é descrito como um instrumento de regulação populista do precariado, uma fração do proletariado que vive entre a insegurança do emprego e a permanente ameaça de exclusão socioeconômica (BRAGA, 2012). Esse precariado, contudo, é visto como um 
grupo com potencial de tomada de consciência de classe, manifestando-se politicamente no questionamento dos valores e práticas neoliberais. E, na medida em que põe em xeque o neoliberalismo, também contesta os aparentes avanços lulistas e sua estabilidade política. Essa constatação é feita pelo autor em sua etnografia de trabalhadores do setor de telemarketing em São Paulo.

Se bem é verdade que possuem escassa experiência política, já começaram a construir suas greves; se não se interessam por partidos, sabem manifestar suas insatisfações dentro e fora das empresas; associam a ampliação do consumo popular à continuidade do Lulismo, mas não se iludem com o "milagre" do crédito subsidiado pelo governo [...] Ou seja, carregam, ainda que em estado latente, o potencial de negação do regime de acumulação pós-fordista (BRAGA, 2012, p. 218).

Singer $(2012 ; 2018)$ também se debruça sobre esse cenário sob outra perspectiva. Para este cientista político, o que chamou de lulismo foi responsável por captar, eleitoral e simbolicamente falando, uma massa empobrecida que é historicamente numerosa no Brasil: o subproletariado. Trata-se, segundo o autor, de indivíduos inseridos de forma precária no mercado de trabalho, transitando entre a formalidade e a informalidade, um grupo social característico da sociedade brasileira e seu desenvolvimento capitalista tardio e estruturalmente desigual. Esse subproletariado, eleitoralmente falando, tende a aderir a líderes que oferecem vantagens a ele, numa relação mais pessoalizada, e em termos de classe é um grupo que deseja melhorias sociais, mas não vê prioridade na redução das desigualdades. Desse modo, não possui condições para tomada de consciência de classe, como outras frações do proletariado; pelo contrário, sua intenção está em deixar de existir (SINGER, 2012).

A análise mais recente de André Singer (2018) sobre um balanço dos governos lulistas expõe a ambiguidade com que estes trataram desse grupo social em ascensão econômica. Ele indica que a balança pendeu para a valorização do mérito do empreendedor em detrimento do reconhecimento coletivo de uma classe trabalhadora fortalecida.

O Lulismo, em vez de esclarecer que a ascensão era fruto de políticas públicas voltadas para as camadas populares, às quais a nova classe trabalhadora pertence, deixou que a ilusão meritocrática, que divide os trabalhadores, se estabelecesse, desviando o olhar para a classe média.

$[\ldots]$ 
Portanto, em lugar de produzir uma mobilização para melhorar a saúde e educação públicas, esse grupo tenderá a acreditar que o Estado, por meio dos impostos e da burocracia, atrapalha sua ascensão individual.

$[\ldots]$

Por outro lado, a plataforma de classe média engancha também na expansão do empreendedorismo nas camadas populares nesta fase do capitalismo financeirizado. Pensar a ascensão como fruto do esforço individual e não da ação coletiva faz sentido para aquele que trabalha por conta própria. [...] Até o trabalhador que vive de bicos, subproletário do setor informal, pode se considerar - e ser considerado - um 'pequeno empreendedor'. (SINGER, 2018, p.96-97).

Outro sociólogo que contesta a formação de uma grande classe média no Brasil recente, mas que também busca desenvolver uma classificação própria sobre a dinâmica social, é Jessé Souza (2012). Este autor enxerga que a camada social em ascensão a partir de 2003 é o grupo dos batalhadores. Esses batalhadores, segundo ele, são uma nova identidade na atividade econômica. Estão logo acima da ralé: indivíduos beneficiados pelas políticas sociais recentes, mas que não possuem oportunidades de ascensão social (SOUZA, 2009). A presença de um capital familiar, em que a solidariedade da instituição da família ajuda a impulsionar as pequenas produções, e uma ética do trabalho (diferente da ética do estudo das classes superiores), na qual se incorporam disposições como disciplina, autocontrole e comportamento e pensamento prospectivo, são as características que permitem aos batalhadores se diferenciarem da ralé e obterem alguma mobilidade social: "[definem-se pela] capacidade de resistir ao cansaço de vários empregos e turnos de trabalho, à dupla jornada na escola e no trabalho, à extraordinária capacidade de poupança e de resistência ao consumo imediato e [...] a uma extraordinária crença em si mesmo e no próprio trabalho" (SOUZA, 2012, p.56).

Souza (2012) analisa os batalhadores pela chave da exploração produtiva na dinâmica entre as classes, na qual as camadas mais altas e a classe média buscam a exploração da ralé e dos batalhadores para a manutenção das desigualdades. Nesse cenário, o lulismo não se apresenta como uma regulação populista desse grupo, mas propriamente um horizonte emancipatório para ele. Apesar, então, de ser crítico à ideia de uma nova classe média, Souza (2012) descreve elementos da subjetividade dos batalhadores que podem ser comparados àqueles mencionados por Neri (2011), principalmente pela ótica do trabalho. A crença em si mesmo e essa ética do trabalho que possuem os batalhadores os aproximam de certo empreendedorismo de base popular. Essa relação de imbricamento é admitida pelo próprio autor: 
Além de uma nova classe trabalhadora definida pelo batalhador/trabalhador, parece existir também uma 'pequena burguesia de novo tipo' representada pelo batalhador/empreendedor. Os limites, entre essas duas frações de classe, em muitos casos são muito fluidos, tornando muito difícil a definição exata de seu pertencimento de classe (SOUZA, 2012, p.56).

É possível perceber nas análises aqui trazidas que não há o desenvolvimento de um perfil de empreendedor bem delineado e compreendido pela teoria social, que seja uma resultante única dos movimentos econômicos e simbólicos experenciados nesse período de maior crescimento brasileiro. As leituras dão conta de indicar certas características culturais importantes, que são próprias da sociabilidade e das práticas históricas entre as classes no Brasil, mas que também assimilam atributos de uma nova razão de mundo e de um discurso voltado à auto-organização dos indivíduos. Assim, os sujeitos que ascenderam recentemente e passaram a ser objeto relevante do estudo social transitam, analiticamente, entre: a busca pela segurança e estabilidade nas formas de trabalho (NERI, 2011), a resistência ao consumo e o desejo de poupança (NERI, 2011; SOUZA, 2012), a crença em si mesmo, o apoio familiar e a persistência em suas atividades (SOUZA, 2012), a resistência a políticas neoliberais e iniciativas precarizantes (BRAGA, 2012) e a valorização do mérito próprio apesar do desejo de melhorias sociais não-estruturais (SINGER, 2012; 2018). Caberá, na exibição e discussão dos resultados, verificar quais desses elementos são mais latentes nas trajetórias expostas e de que forma é possível pensar em composições entre si.

\section{O discurso empreendedor na sociedade neoliberal}

Antes de descrever as trajetórias que serão analisadas, consideramos importante admitir que a figura do empreendedor, peça importante desse cenário retratado, é parte do contexto de uma sociedade neoliberal, que buscou retomar o empreendedorismo e ressignificá-lo à sua razão.

Como descrevem Dardot e Laval (2016) a partir de uma interpretação da obra de Foucault (2008), O Nascimento da Biopolítica, o neoliberalismo se coloca não como uma ideologia ou um novo sistema político, mas propriamente como uma razão de mundo. Esta não atua simplesmente modificando políticas econômicas e reduzindo a intervenção estatal em certas áreas, como um liberalismo clássico revisitado, mas sim criando um novo modo de governar os sujeitos e as instituições. Isso implica em reconhecer outra gramática na análise sobre os Estados, as empresas e os indivíduos. 
Essa gramática é pautada por uma aplicação do modelo-empresa como configuração universal, aplicável a todos os sujeitos e instituições, e como consequência, a concorrência surge enquanto uma norma que rege as relações sociais entre essas empresas-indivíduo. Ao fundo, trata-se de reconhecer no mercado um agente de subjetivação, ou seja, um produtor de novos sujeitos condicionados segundo seus moldes morais e sociais. Com isso, torna-se compreensível a associação do discurso sobre o empreendedorismo enquanto prática incentivadora da organização empresarial entre indivíduos.

É preciso pontuar, entretanto, que esse empreendedorismo próprio da razão neoliberal não é o mesmo que o retratado por Joseph Schumpeter (1961) ao observar o capitalismo do final do século XIX e início do século XX. Segundo esse economista, a figura do empreendedor seria uma espécie de motor do sistema econômico, capaz de provocar inovações, ou empreendimentos, que permitissem seu desenvolvimento. Essas inovações poderiam ser a introdução de um novo bem ou de um novo método de produção, a abertura de um novo mercado, a conquista de uma nova fonte de matériasprimas, ou uma nova organização de qualquer indústria (SCHUMPETER, 1961, p.76). Assim, o indivíduo capaz de empreender deveria ter atributos específicos, como a força de vontade, o enfrentamento de uma oposição do ambiente social em que está inserido, uma capacidade de liderança, além de ter uma motivação baseada não no lucro ou na satisfação de necessidades pessoais, mas na alegria de criar e fazer coisas (SCHUMPETER, 1961). Um ponto importante dessa descrição é observar o fato de que o empreendedorismo de Schumpeter (1961) não pode, então, ser considerado uma profissão ou uma classe específica. E dificilmente ele apresenta uma condição duradoura, pois está mais associado a um modo de agir, vinculando-se a um grupo seleto (e necessariamente restrito) de indivíduos, e organizado apenas em determinadas situações e momentos.

O empreendedor do neoliberalismo é, portanto, radicalmente distinto do descrito por Schumpeter (1961) principalmente pelas diferenças de abrangência dessa figura. Na sociedade neoliberal, o empreendedorismo é tido como um fenômeno de massas: "Todo indivíduo tem algo de empreendedorístico dentro dele, e é característica da economia de mercado liberar e estimular esse empreendedorismo humano." (DARDOT e LAVAL, 2016, p.145, grifo do autor). A noção de indivíduos com capacidade de liderança e força de vontade para enfrentar barreiras contextuais encontradas, desenvolvida por Schumpeter (1961), é propagada contemporaneamente como uma atitude perante a sociedade neoliberal, que todos podem (e precisam) desenvolvê-la. 
López-Ruiz (2007) também nos ajuda a entender esse processo de expansão do empreendedorismo. $\mathrm{O}$ autor analisa o ethos de executivos de transnacionais, buscando retratar, sob uma leitura weberiana, um novo espírito do capitalismo. Segundo ele, nesse novo espírito capitalista o empreendedorismo se coloca enquanto a atitude de um povo:

O empreendedorismo passou a ser a atitude de um povo, a atitude que se espera de um povo, como anuncia hoje uma vasta literatura de gestão de negócios. O que isto quer dizer? Em primeiro lugar, que o sistema econômico já não precisa de alguns poucos homens de negócios empreendedores que tomem nas suas mãos as rédeas do desenvolvimento econômico. O que o sistema econômico precisa é de uma ética empresarial do trabalho. Isto é, precisa de um conjunto de valores e normas que seja compartilhado dentro de uma sociedade, a partir do qual quem trabalha seja levado a pensar e a sentir a sua atividade como uma empresa particular e como o motivo principal da sua vida. (LÓPEZ-RUIZ, 2007, p.30, grifo do autor).

Neste sentido, torna-se compreensível observar como muitas interpretações recentes sobre a dinâmica social brasileira vêm acompanhadas de referências ao empreendedorismo e como as classes populares dialogam com esse fenômeno. Contudo, é importante considerar os efeitos desse projeto universal do discurso empreendedor. Ao se propor totalizante, é de se esperar que esse discurso esbarre em certas formações sociais e práticas entre os indivíduos que configuram resistências, hibridizações e mesmo novas categorias de apropriação. Entender a transição do assalariado fordista ao empreendedor do neoliberalismo implica em reconhecer permanências de certos modos de socialização, assim como a estruturação de certas sociedades impacta no quanto (e como) esses atributos de uma sociedade neoliberal serão assimilados. O caso brasileiro é um exemplo bastante elucidativo. Como falar de uma massa de assalariados, ou de empreendedores, a depender do período, quando o contexto histórico nacional dá conta de descrever a permanência estrutural da informalidade e do subemprego (THEODORO, 2005; SINGER, 1985) no mercado de trabalho? Assim, o discurso sobre o empreendedorismo no Brasil já vem carregado de ambiguidades e redefinições.

Simultaneamente, ao abarcar grupos sociais heterogêneos, o discurso empreendedor assume facetas aparentemente ambíguas e pode ser interpretado de diferentes maneiras, como pontuou Colbari (2007). Por vezes pode se apresentar como um horizonte emancipatório para grupos historicamente excluídos na sociedade brasileira, como negros e mulheres, que se sentem autônomos ao galgar maior reconhecimento nessa sociedade, e outras vezes se apresenta como uma perspectiva de 
precarização para a classe trabalhadora ao retirar mecanismos de solidariedade e proteção coletiva, interferindo em direitos historicamente conquistados.

Gago (2018) busca pensar a dinâmica resultante desses encontros entre discurso neoliberal e práticas sociais. A autora utiliza um vocabulário político que nos permite pensar:

uma dinâmica transindividual de forças produtivas, que a todo o tempo transbordam o esquema neoliberal e antecipam possibilidades que já não são as socialistas estatais. Ou seja, é um modo de cooperação social que reorganiza o horizonte do trabalho e da exploração, da integração e do progresso, da boa vida e do bom governo. (GAGO, 2018, p.25).

Gago (2018) considera que há duas topologias possíveis numa interpretação do neoliberalismo. A primeira é o neoliberalismo de cima pra baixo, relacionado a uma mudança no regime de acumulação global que implica em novas estratégias e ações por parte de instituições nacionais. A segunda é o neoliberalismo de baixo para cima, ou desde baixo, que enxerga a razão neoliberal como algo que se desenvolve sob o tecido social e que se encontra além da vontade de um governo, e por isso mesmo permite combinações e imbricamentos não dimensionados por uma lógica de cima para baixo.

Destacar a importância de dinâmicas que transbordam a razão neoliberal e, portanto, indicam limites e contornos à expansão do discurso empreendedor nesses moldes, nos permite pensar que a aparente pluralidade de interpretações sobre o Brasil recente, descrita na seção anterior, pode apresentar certo grau de convergência. Se o empreendedorismo contemporâneo assume pretensões universalizantes e, nesse processo, assimila diversas facetas, supõe-se que as camadas populares se tornem também o reflexo dessa heterogeneidade.

\section{As trajetórias de oito empreendedores e empreendedoras populares}

A descrição das narrativas expostas a seguir buscará não apenas ilustrar essa heterogeneidade, mas principalmente notar permanências e questões contundentes para o grupo social analisado. Assim, poderemos, ao fim, indicar novos caminhos e interpretações sobre esse empreendedor popular do Brasil recente.

Utilizamos um olhar para as trajetórias de vida dos entrevistados, concentrandonos na compreensão de elementos biográficos, socioculturais e simbólicos dos indivíduos. A técnica de pesquisa que motivou esse olhar é conhecida como histórias de 
vida, que, segundo Paulilo (1999), nos possibilita compreender a cultura "do lado de dentro", situando-se entre "o que é exterior ao indivíduo e aquilo que ele traz dentro de si" (PAULILO, 1999, p.142). Desse modo, o universal se mostra no singular, pois é feito um resgate das vivências pessoais profundamente enraizadas na sociedade. Esse resgate é importante na medida em que revela componentes intrínsecos das subjetividades estudadas, que podem apresentar contradições e complexidades não captadas em análises mais superficiais sobre o tecido social, que não consideram a trajetória biográfica e a vivência dos entrevistados.

Foram realizadas, entre novembro e dezembro de 2018, entrevistas semiestruturadas com quatro mulheres e quatro homens da Grande São Paulo que trabalham autonomamente em pequenos empreendimentos. Para captar indivíduos impactados pelas políticas sociais do lulismo, a fim de observar a germinação de certo tipo de empreendedor popular, utilizamos o recorte de renda proposto por Quadros (2008) ao estratificar a sociedade brasileira em termos de renda e tipos de ocupação. Este economista analisou microdados da Pesquisa Nacional por Amostra Domiciliar (PNAD) para determinar cinco "padrões de vida" na sociedade brasileira de 2008, mas que podemos transportar para o Brasil contemporâneo, segundo Singer (2018). Quadros (2008) apontou os seguintes grupos: alta classe média, média classe média, baixa classe média, massa trabalhadora, e miseráveis ${ }^{2}$.

Esses padrões de vida foram vinculados a grupos ocupacionais, possibilitando uma intersecção importante. Os grupos eram: (A-1) Empregadores com mais de 10 empregados; (A-2) Empregadores com até 10 empregados; (C) "Colarinhos brancos" autônomos; (D) "Colarinhos brancos" assalariados; (F) Trabalhadores autônomos; (G) Trabalhadores assalariados; (I) Trabalhadores domésticos; (J-1) Trabalhadores não remunerados urbanos; (H-1) Proprietários conta própria agrícolas; (H-2) Trabalhadores autônomos agrícolas; (H-3) Trabalhadores assalariados agrícolas; e (J-2) Trabalhadores não remunerados agrícolas (QUADROS, 2008). Essas intersecções consideram que pode haver trabalhadores autônomos compondo tanto o padrão de vida da alta classe média, como o da massa trabalhadora, por exemplo. Assim, é importante notar quais profissões estão sendo englobadas na ocupação dos autônomos, por exemplo, dentro do padrão da alta classe média. Estas profissões podem mudar radicalmente se alterarmos os padrões de vida.

Adotando, portanto, o recorte de Quadros (2008) e as considerações de Singer (2018) sobre ele, buscamos indivíduos que estivessem no grupo da baixa classe média

\footnotetext{
2 Segundo o autor, os ricos não estão incluídos, pois tendem a dissimular sua condição social, transmitindo um perfil de alta classe média (QUADROS, 2008).
} 
e da massa trabalhadora, o que Singer $(2012 ; 2018)$ chamou de subproletariado, aproximando-se, principalmente em termos econômicos, dos grupos descritos por Neri (2011), Braga (2012) e Souza (2012). Trabalhamos, com a ocupação de autônomos, profissões mais relacionadas ao mundo do empreendedorismo. Privilegiamos indivíduos que tivessem de lidar com o planejamento e as finanças de seu próprio negócio, vivendo de seus próprios rendimentos e se organizando economicamente de forma independente. Para os valores de outubro de 2018, essa camada tinha indivíduos cujo rendimento mensal médio estava entre $\mathrm{R} \$ 563,19$ e R $\$ 2.815,94$. Essa classificação não considerou rendimento familiar, de modo que outras pessoas da família poderiam desempenhar ocupações de variadas rendas. Mas ao buscar indivíduos que tinham em seus negócios sua única fonte de renda individual, acreditamos ter atingido as camadas sociais desejadas. Apenas duas exceções ao critério de renda foram feitas: a de Antônio e Mariana ${ }^{34}$. Ambos ultrapassavam marginalmente a faixa estipulada, mas encaixavamse nas ocupações pretendidas, e tinham elementos culturais que enriqueciam a análise. Antônio, por exemplo, é um vendedor ambulante de muitos anos no centro de São Paulo, e Mariana tinha na vivência do empreendedorismo um horizonte de emancipação e insumo para a luta contra o racismo.

Dentro do roteiro de entrevista, foram pensados quatro eixos que conduziram a narrativa desses indivíduos: trajetória pessoal e profissional, meio do empreendedorismo, mercado de trabalho e questões econômicas, e sociedade e Estado. Esses eixos foram baseados na literatura sobre as transformações sociais do Brasil recente e sobre o empreendedorismo aos moldes contemporâneos. Assim, buscamos investigar como (e se) as pessoas se consideravam empreendedoras, verificando se mobilizavam conceitos ligados ao mundo corporativo, se participavam de grupos de empreendedores nas redes sociais ou outros meios de contato, ou se mencionavam profissionais vistos na opinião pública como empreendedores de sucesso. Mas também procuramos analisar suas percepções políticas, trajetória profissional, conjuntura familiar e como enxergavam simbólica e culturalmente a sociedade brasileira contemporânea.

Descreveremos brevemente a seguir o perfil de cada um dos entrevistados e na seção seguinte faremos uma análise geral de pontos em comum e conteúdo de destaque

\footnotetext{
3 No caso de Mariana, no momento da entrevista, ela estava recém-empregada como assalariada, mantendo seu negócio em paralelo, o que em teoria fugia dos critérios estabelecidos. Mas consideramos que sua vivência enquanto autônoma, bem como as questões culturais levantadas, poderia ser de grande contribuição ao estudo.

${ }^{4}$ Para garantir o anonimato dos entrevistados, os nomes utilizados aqui não correspondem aos reais nomes das pessoas.
} 
sobre essa subjetividade empreendedora, apontando caminhos possíveis para pensar esse novo sujeito.

Luciana, a primeira entrevistada, vende seu próprio artesanato numa feira de rua aos domingos e por encomenda em sua casa. Ela foi assalariada por um breve tempo, mas tornou-se dona de casa quando se casou. Quando o marido perdeu o emprego na indústria automobilística, ele buscou se tornar autônomo vendendo lanches num food truck, e ela decidiu vender o artesanato que sempre gostou de fazer. Hoje os dois são separados, mas o marido, reinserido na indústria, a ajuda constantemente. Luciana não mobiliza muitos conceitos ligados ao empreendedorismo, mas o vê de forma positiva. Parece aceitar a rotina enquanto autônoma, mas se queixa da baixa quantidade de vendas, e diz que preferiria não trabalhar por conta própria, pela falta de disciplina que essa atividade provoca e a carga horária que acaba ultrapassando a de um trabalho formal ("Eu não consigo... porque meu horário teria que ser um dia muito maior pra eu poder fazer tudo."). Politicamente, não tem uma boa imagem de instâncias coletivas como os sindicatos, mas apesar de admitir "conhecer pouco", não condena políticas de distribuição de renda como o PBF.

André é um jovem de 23 anos que trabalhou em diversas funções e lugares: numa rede de fast-food; como vendedor em loja de roupas; em empresas de crédito consignado; no chão de fábrica; e como atendente de telemarketing. Mas descobriu seu ramo na confecção de cosméticos. Trabalhou por um tempo numa loja relacionada, e decidiu começar a fabricar suas próprias essências e perfumes. Começou vendendo-os nas ruas do centro de São Bernardo do Campo numa sociedade com alguns familiares, e acabou montando uma pequena loja numa galeria da mesma região. De todos os entrevistados, André é o mais inserido no meio do empreendedorismo: mobiliza conceitos e pensamentos e está sempre inteirado das novidades sobre o meio, seguindo pessoas que o inspiram. Para ele, empreendedor é aquele que "bota a cara" e "vai correr atrás": "O empreendedor é a luta diária. Aqui você tem que se rebolar pra você não deixar a peteca cair". André demanda do Estado um papel ativo no estímulo à atividade econômica, seja reduzindo impostos de pequenos empreendedores, seja aumentando a renda da população, como forma de incentivo ao consumo.

Teresa é uma migrante nordestina que, vinda ainda nova para São Paulo, trabalhou por muito tempo como funcionária de um hospital, e saiu quando ganhou seu segundo filho e quando começaram as terceirizações de serviços relacionados e, com elas, a redução salarial e demissão de colegas. Foi ainda para o ramo da tecelagem, mas decidiu se dedicar aos afazeres domésticos e cuidar de sua saúde, deixando a vida de assalariada. Chegou também a trabalhar como babá, mas abriu seu negócio há cerca de 13 anos atrás. Teresa, que quando assalariada já revendia produtos de amigas e amigos 
para outros colegas, decidiu transformar sua garagem numa pequena vendinha de bairro. Vende produtos alimentícios de uso cotidiano, mas também materiais de papelaria, algumas roupas e perfumes. Assim como Luciana, vê positivamente o meio empreendedor, mas pouco mobiliza sobre o conceito, não se enxergando como tal de início. Teresa encara o trabalho formal como algo importante a se alcançar se a pessoa "tiver estudo". De modo geral, apresenta certa resignação com a informalidade e as incertezas de se trabalhar por conta própria, até pelas dificuldades do mercado de trabalho: "Antes, eu achava assim, era mais fácil pra gente conseguir um emprego, num era tudo tão difícil... Hoje tá mais difícil, assim... num é, eu acho que tem o trabalho, tem o serviço. Mas hoje estão exigindo muito em termo de especialização". Sua demanda social principal é o acesso facilitado ao crédito, já que considera os juros atuais muito abusivos.

Fabíola é uma dona de casa que vende marmitas fitness para pessoas e grupos interessados. Sempre gostou de cozinhar e decidiu explorar esse ramo depois que fez um curso em seu bairro cuja intenção é desenvolver capacidades empreendedoras em pessoas de regiões periféricas. Ela trabalhou como assalariada na parte administrativa de pequenos negócios e decidiu se tornar dona de casa quando se casou, porém continuou contribuindo com a renda familiar, vendendo comidas variadas em sua região. Seu marido também "é empreendedor", e possui uma corretora de seguros há mais de 25 anos. Fabíola também é recém-formada em Serviço Social, mas encontrou dificuldades em seu ramo profissional, não exercendo a função. Por conta do curso que fez, seus conhecimentos sobre o meio do empreendedorismo são amplos e aparentam significar um horizonte importante para ela. Politicamente, apresenta uma visão moderada sobre políticas sociais e instâncias coletivas, como os sindicatos: "Ao mesmo tempo que é bom, é ruim porque é uma lavagem de dinheiro danada.”.

Mariana se diferencia bastante das mulheres descritas até aqui. Ao contrário de Luciana, Teresa e Fabíola, ela não passou a ter um negócio próprio pelas atividades que fazia em casa, conciliando a jornada doméstica do casamento com suas habilidades no artesanato ou na culinária. Mariana, mais nova que as três mencionadas, vive com seus pais na periferia da Zona Norte paulistana, e passou a "empreender" por outros motivos. Ao fazer um curso de MBA na FGV sobre empreendedorismo e participar da militância negra e feminista, identificou um nicho de mercado importante e que se encaixava à sua formação profissional como bibliotecária. Hoje ela possui uma livraria especializada em literatura feminista e, principalmente, negra. Sua vida profissional foi permeada por bicos e atividades formais, e ela não aparenta assimilar uma valorização pelo trabalho enquanto algo dignificador. Em sua perspectiva, o empreendedorismo estaria muito mais além do que um novo modo de condução da vida profissional, representando um 
modelo próprio de questionamento dos lugares dos negros e das mulheres na sociedade: "A gente poderia ter muito mais pessoas que fossem empreendedoras. Mas ao mesmo tempo a gente é uma ameaça. Eu sou uma ameaça, assim. Por ser mulher, por ser mulher negra, periférica... e o mercado, ele não me quer."

Antônio é um ambulante que trabalha há 12 anos na famosa Feira da Madrugada, no centro de São Paulo. Ele vende cuecas no lado de fora da feira, que segundo ele atrai mais público do que os boxes internos do espaço, que depois de reformulado deixou de ser atrativo, segundo seus relatos. Antônio trabalhou na indústria, numa fábrica de brinquedos, e foi dos últimos funcionários a sair de lá depois de sua falência. Depois ainda trabalhou numa empresa de ferro e aço, mas saiu temendo por sua saúde, por conta dos pesos que carregava. Ele aparenta estar adaptado e desfrutar da rotina agitada como ambulante ("na rua é gostoso demais!"), não vendo perspectivas de retornar ao trabalho formal. Também vê o empreendedorismo como uma categoria positiva, mas não possui referências sobre o meio ou se enxerga como empreendedor a priori. Sua família auxilia no negócio em períodos de maior venda, e uma de suas principais preocupações é garantir o estudo de suas duas filhas ("tem que fazer o que eu não fiz"). Politicamente, Antônio exprime um esgotamento do petismo em termos eleitorais. Para ele, que antes de 2018, havia votado sempre no Partido dos Trabalhadores (PT), era hora de mudar, buscando melhorar a administração do país e acabar com a corrupção.

Lucas é formado em turismo. Trabalhou em agências, hostels e pousadas. E na adolescência ocupou vagas administrativas, como auxiliar, em departamentos de vendas e no telemarketing. Hoje não pensa em retornar ao mercado formal: criou um pequeno negócio de marcenaria, fabricando móveis de madeira sob encomenda, para residências e estabelecimentos. Para ele, as amarras do mundo assalariado não compensam os ganhos financeiros que ele oferece: "É porque eu comecei a ver o mercado de trabalho com outros olhos. E a forma que a gente é valorizado dentro duma empresa." Hoje parece ter se encontrado em seu empreendimento, ainda que tenha pouco tempo para descanso. Lucas é jovem e mora com os pais na periferia da Zona Oeste de São Paulo, que hoje incentivam o negócio, mas de início demonstraram certo descrédito. Ele mobiliza conceitos e termos do empreendedorismo, que vê de forma bastante positiva. Inclusive fornece cursos ligados à atividade que executa e sob uma ótica empreendedora. Entretanto, não está completamente inserido nessa rede, pois não frequenta cursos ou conhece muitas pessoas do ramo. Lucas tem uma imagem dos sindicatos associada às colônias de férias e demanda do Estado a descentralização das empresas na cidade, estimulando bairros mais periféricos, além de considerar importante a redução da burocracia de forma generalizada. 
Carlos possui uma trajetória que pode ser bastante ilustrativa do que no imaginário social corresponde à trajetória de um empreendedor. Trabalhou como ajudante de supermercado na adolescência e aspirou fazer um curso técnico de mecânica industrial no Serviço Nacional de Aprendizagem Industrial (SENAI). Quando conseguiu passar, formou-se e foi trabalhar na área, especializando-se em manutenção de equipamentos hospitalares e odontológicos. Numa das empresas que atuou, viu uma oportunidade profissional inovadora, criando sua própria empresa de prestação de serviços de manutenção para consultórios de dentistas. $\mathrm{O}$ dono de onde até então trabalhava não havia aceitado a proposta de Carlos de expandir as marcas atendidas e o tipo de atendimento oferecido. Nesse sentido, teve uma ideia disruptiva e criou algo novo, um empreendimento, como pontua a cartilha de Schumpeter (1961). Ele mobiliza certos valores e concepções do meio empreendedor, e tem na figura do trabalhador uma imagem de algo ultrapassado, uma categoria pertencente a outras épocas. Hoje ele mora sozinho na periferia da Zona Leste paulistana e possui uma cartela de clientes em consultórios oferecendo seus serviços de manutenção. Carlos sente que se envolve pouco em questões políticas e sociais por falta de tempo, e possui uma imagem sobre políticas sociais bastante parecida com a dos demais entrevistados: positiva, desde que com rigor nos cadastros dos benefícios. O mesmo ocorre com o sindicato. Segundo Carlos, "com ele ruim, sem ele pior".

Uma questão que também buscamos analisar em todas essas entrevistas foi como essas pessoas se organizavam profissionalmente em seus meios, principalmente se tinham na concorrência uma norma fundamental de ação, como propõe a razão neoliberal descrita por Dardot e Laval (2016). Com as devidas variações, já que algumas atividades exigiam mais contato entre os profissionais do ramo e outras menos, notamos que a concorrência aparece como uma questão marginal na organização das atividades dos entrevistados, mais como uma realidade do mercado do que uma preocupação do dia-a-dia. Na verdade, percebeu-se grande solidariedade nas falas e nas práticas descritas entre os entrevistados. Muitos ajudavam colegas a entrarem no mesmo ramo ou então compartilhavam clientes, indicando barreiras importantes à ideia de uma organização puramente baseada no modelo empresarial concorrencial.

\section{Um empreendedor híbrido por concepção}

A questão da concorrência é o gancho para começarmos a explicar o tipo de empreendedor popular que se formou no Brasil recente. Como a descrição das trajetórias aponta, o empreendedorismo é visto de forma positiva, e em alguns casos dotado de 
completo sentido para a realidade profissional dos indivíduos. Por conta de seus status enquanto autônomos e, de certa forma, distantes do trabalho formal e assalariado, enxergar-se como uma empresa de si que precisa "correr atrás" e "se virar" é uma perspectiva realista e necessária. Mas a forma de lidar com a concorrência e o modo como passam a se verem como empreendedores - mais como uma categoria que ajuda a explicar a condição atual do que uma identidade profissional consolidada - indica que o discurso empreendedor aos moldes da razão neoliberal não é plenamente incorporado.

O que se observa, em geral, são indivíduos que transitaram entre o trabalho formal assalariado e ocupações informais e, seja pelo desejo de se desvencilhar das amarras disciplinares e fazer o que gosta, seja pela dificuldade em retomar postos nesse meio assalariado, os indivíduos acharam no empreendedorismo uma categoria que os contemplasse, até pela abrangência discursiva que ela se propõe. Como resultante, o empreendedor popular no Brasil recente possui uma série de clivagens que o categorizam: as entrevistadas demonstram (com exceção de Mariana) que as mulheres, pelo machismo estrutural, estão mais associadas à ideia de serem uma renda complementar na família ao desenvolverem atividades de cunho doméstico; os mais jovens possuem maior adesão aos conceitos e referências do meio empreendedor, muitas vezes contrapondo-o a uma concepção tradicional e considerada obsoleta sobre o trabalho (em geral o assalariado); e aqueles pertencentes a grupos historicamente excluídos, como os negros, podem enxergar no empreendedorismo um horizonte emancipatório ao garantir oportunidades a grupos marginalizados no mercado de trabalho, como o relato de Mariana exemplifica.

Pelas trajetórias analisadas, vemos que alguns elementos simbólicos destacados por Neri (2011) em seu diagnóstico sobre a nova classe média são pertinentes. Mesmo encarando uma realidade profissional que prescinde de estabilidade e garantias sociais, os entrevistados demonstraram um apego a essas questões, pontos suficientes para um eventual retorno à vida assalariada, segundo a maioria dos entrevistados. O desapego ao consumo e a necessidade de poupança (NERI, 2011; SOUZA, 2012) não foram elementos muito mobilizados nas entrevistas, porém a constante preocupação com os rendimentos mensais extraídos pode indicar esforços de poupança significativos, mas também um desejo de maior conforto material propiciado por novos padrões de consumo.

A persistência e a crença em si mesmo (SOUZA, 2012) foram questões muito mobilizadas, comportamentos quase que obrigatórios para iniciarem suas atividades e, principalmente, continuarem as desenvolvendo. Souza (2012) destacou também a questão familiar nessas atividades, e foi um componente bastante observado em algumas entrevistas. Luciana, por exemplo, tem auxílio de seu ex-marido para continuar 
vendendo seus produtos. André montou seu negócio inicialmente numa sociedade com familiares. Teresa, por sua vez, tem ajuda de seu filho na organização de suas vendas. Já Antônio, conta com a família em períodos mais movimentados no comércio ambulante.

Politicamente, a análise que fez Singer (2012) sobre o subproletariado parece também indicar importantes tendências desse grupo. Os entrevistados, pela percepção que possuíam sobre instâncias de regulação como os sindicatos e programas de distribuição de renda, não manifestaram grandes aspirações coletivas e apontaram para melhorias sociais não-estruturais ao demonstrarem apoio a políticas como o Bolsa Família e o Benefício de Prestação Continuada. Neste sentido, dialogaram positivamente com as iniciativas empreendidas pelos governos Lula e Dilma, demandando, contudo, o aprofundamento dessas medidas. Teresa, por exemplo, manifestou dificuldade de acesso ao crédito. André indicou para a necessidade de aumento da renda dos mais pobres, para que aumentasse o consumo. Outra pauta muito incidente foi a diminuição da burocracia e a facilitação dos caminhos formais para empreendedores, elementos mais próprios de discursos que valorizam o aspecto individual, muitas vezes vinculados à razão neoliberal e seus agentes de difusão.

O panorama aqui exposto se distancia do proposto por Braga (2012) quanto à capacidade que os indivíduos analisados possuem de contestação das políticas neoliberais. Questões como o reconhecimento de limites dos avanços lulistas, ao demandarem ações mais incisivas e de caráter permanente, e a identificação de situações precarizantes, como a quantidade de horas que acabam por trabalhar a mais e as garantias que o trabalho autônomo não proporciona, ainda que eles não consigam se desvencilhar dessas amarras profissionais, estão mais próximas de um reconhecimento das dificuldades materiais das atividades que desempenham do que uma percepção política do fenômeno.

\section{Considerações finais}

De todo modo, as interpretações sobre as transformações sociais brasileiras entre 2003 e 2014 dão conta de apontar para um empreendedor aparentemente ambíguo e bastante diverso daquele pensado pelo neoliberalismo. E as trajetórias aqui trazidas exemplificam e confirmam essas diferenças, bem como as características da razão neoliberal que foram incorporadas. Pela conjuntura do mercado de trabalho brasileiro e global, é possível que a categoria de empreendedor permaneça como importante conceito para a descrição das atividades profissionais das camadas populares, já que é 
dos poucos termos que fazem algum sentido para uma população tão abrangente e diversa.

Assim, podemos confirmar a ideia de que as políticas lulistas criaram as condições para a emergência de um tipo empreendedor nas camadas populares, se não aos moldes de um discurso próprio da razão neoliberal, então mais como uma categoria que ajudasse a explicar o meio profissional e os modos de sobrevivência dos sujeitos impulsionados por esses governos. Ao servir como categoria analítica, vemos também que o empreendedor germinado no Brasil recente sinaliza para a ilusão meritocrática que apontou Singer (2018), mas compartilha de práticas populares que transbordam o esquema neoliberal (GAGO, 2018), como ilustra a questão do (ausência de) senso de concorrência nos entrevistados.

O legado simbólico das recentes transformações socioeconômicas brasileiras, assim como o contexto histórico e as práticas e dinâmicas populares, continuarão sendo elementos fundamentais de ressignificação desse empreendedorismo, dando origem a uma forma híbrida que necessita maior aprofundamento. Cabe a estudos e análises futuras considerar novas categorias analíticas, para além do empreendedorismo, a fim de descrever esse sujeito tão importante para se pensar a sociedade brasileira contemporânea e os modos de vida em relação ao mundo do trabalho.

\section{THE GERMINATION OF CONTEMPORARY BRAZILIAN ENTREPRENEUR: NEOLIBERALISM SEEN ACCORDING TO THE RECENT NATIONAL CONTEXT}

ABSTRACT: The article presents a discussion about the development of a specific type of entrepreneur in contemporary Brazilian society. The social and economic advances of the Lulism's governments have enabled the income growth of a significant part of the Brazilian population which, by acquiring new ways of life, also saw their cultural references being transformed. Particularly, the picture of the entrepreneur became representative of the new Brazilian reality. In the context of a neoliberal society, where the companies and the norm of competition propose universal, the meaning of entrepreneurial symbolism has become even more latent. However, in contemporary Brazil there was a type of entrepreneur distinct from the one pictured by neoliberal discourse. To show these differences, eight trajectories of popular Brazilian entrepreneurs were mobilized, and in the end, important ambiguities and new categories of values and actions could be identified, constituting a characteristic entrepreneur of recent Brazil. 
KEYWORDS: Entrepreneurship. Neoliberalism. Lulism. Popular classes. New Brazilian Middle Class.

\section{LA GERMINACIÓN DEL EMPRENDEDOR BRASILEÑO CONTEMPORÁNEO: EL NEOLIBERALISMO VISTO EN EL CONTEXTO NACIONAL RECIENTE}

RESUMEN: El artículo presenta una discusión sobre el desarrollo de un tipo especifico de emprendedor en la sociedad brasileña contemporánea. Los avances sociales y económicos de los gobiernos lulistas permitieron un aumento significativo en los ingresos de una parte importante de la población brasileña, que, al adquirir nuevas formas de vida, también vio transformarse sus referentes culturales. En el contexto de una sociedad neoliberal, donde las empresas de si mismas y la regla de la competencia se proponen como universales, el significado del simbolismo empresarial se ha hecho aún más latente. Sin embargo, en el Brasil contemporáneo se observó un tipo de emprendedor distinto al retratado por el discurso neoliberal. Para mostrar estas diferencias, se movilizaron ocho trayectorias de emprendedores populares brasileños $y$, al final, se pudieron identificar importantes ambigüedades y nuevas categorías de valores y acciones, configurando un emprendedor característico del Brasil reciente.

PALABRAS CLAVE: Emprendimiento. Neoliberalismo. Lulismo. Clases populares. Nueva clase media brasileña.

\section{REFERÊNCIAS}

BOLTANSKI, Luc e CHIAPELLO, Ève. O novo espírito do capitalismo. São Paulo: Martins Fontes, 2009.

BRAGA, Ruy A política do precariado: do populismo à hegemonia lulista. São Paulo: Boitempo. 2012.

BRASIL. IPEA - Instituto de Pesquisa Econômica Aplicada. IPEA DATA. Disponível em: http://www.ipeadata.gov.br/. Acesso em: 01 out. 2020.

COLBARI, Antônia. A retórica do empreendedorismo e a formação para o trabalho na sociedade brasileira. SINAIS - Revista Eletrônica - Ciências Sociais. Vitória, n. 1, v. 1, p.75111, 2007. 
CRUZ JUNIOR, Brauner Geraldo. A empresa de si mesmo: A assimilação do discurso empreendedor pelas camadas populares brasileiras. Orientador: Claudio Luis de Camargo Penteado. 2019. 188p. Dissertação (Mestrado). Universidade Federal do ABC, São Bernardo do Campo, 2019.

CURY Anay; SILVEIRA, Daniel. PIB brasileiro recua 3,6\% em 2016 e tem pior recessão da história. G1. Publicado em 07 de março de 2017. Disponível em:

https:/g1.globo.com/economia/noticia/pib-brasileiro-recua-36-em-2016-e-tem-pior-recessaoda-historia.ghtml. Acesso em: 01 out. 2020.

DARDOT, Pierre e LAVAL, Christian. A nova razão do mundo: ensaios sobre a sociedade neoliberal. São Paulo: Boitempo, 2016.

FARIZA, Ignacio; MONTES, Rocio. Impulsionada pelo Brasil, extrema pobreza na América Latina tem pior índice em dez anos. El País, Brasil. Publicado em 16 de janeiro de 2019.

Disponível em:

https://brasil.elpais.com/brasil/2019/01/15/internacional/1547563856_964646.html. Acesso em: 01 out. 2020 .

FOUCAULT, Michel. Nascimento da Biopolítica: curso dado no Collège de France (19771978). São Paulo: Martins Fontes, 2008.

G1. Economia brasileira cresce 7,5\% em 2010, mostra IBGE. Globo. Publicado em 04 de março de 2011. Disponível em: http://g1.globo.com/economia/noticia/2011/03/economiabrasileira-cresce-75-em-2010-mostra-ibge.html. Acesso em: 01 out. 2020.

GAGO, Verónica. A razão neoliberal: economias barrocas e pragmática popular. São Paulo: Elefante, 2018.

GUIMARÃES, José Soares. Perfil do trabalho decente no Brasil: um olhar sobre as Unidades da Federação. Brasília: Organização Internacional do Trabalho (OIT), 2012.

KERSTENETZKY, Célia Lessa. Foi um pássaro, foi um avião? Redistribuição no Brasil no século XXI 1. Novos Estudos CEBRAP, São Paulo, n. 2, v.36, p.15-34, 2017.

LÓPEZ-RUIZ, Osvaldo. Os executivos das transnacionais e o espírito do capitalismo: capital humano e empreendedorismo como valores sociais. Rio de Janeiro: Azougue, 2007.

MACHADO, Luiz Antonio. Da informalidade à empregabilidade: reorganizando a dominação no mundo do trabalho. Caderno CRH, Salvador, n. 37, v.15, p. 81-109. 2002.

NERI, Marcelo. A nova classe média: o lado brilhante da base da pirâmide. São Paulo: Saraiva, 2011.

PAULILO, Maria Angela. A pesquisa qualitativa e a história de vida. Serviço social em revista. Londrina, n. 1, v.2, p.135-145, 1999.

POCHMANN, Márcio. O mito da grande classe média: capitalismo e estrutura social. São Paulo: Boitempo, 2014. 
QUADROS, Waldir. A evolução da estrutura social brasileira: notas metodológicas. Texto para discussão. IE/UNICAMP, Campinas, n. 147, 2008.

RDA - Rede Brasil Atual. Desemprego em São Paulo recua com trabalho autônomo e doméstico. Publicado em 29 de janeiro de 2019. Disponível em: https:/www.redebrasilatual.com.br/economia/2019/01/desemprego-em-sao-paulo-recua-comtrabalho-autonomo-e-domestico. Acesso em: 01 out. 2020.

SCHUMPETER, Joseph. Teoria do desenvolvimento econômico. Rio de Janeiro: Fundo de Cultura, 1961.

SINGER, André. O lulismo em crise: um quebra-cabeça do período Dilma (2011-2016). São Paulo: Companhia das Letras, 2018.

SINGER, André. Os sentidos do lulismo: reforma gradual e pacto conservador. São Paulo: Companhia das Letras, 2012.

SINGER, Paul. Economia Política da Urbanização. São Paulo: Brasiliense, 1985.

SOUZA, Jessé. Os batalhadores brasileiros: nova classe média ou nova classe trabalhadora? Belo Horizonte: Editora UFMG, 2012.

SOUZA, Jessé. A ralé brasileira: quem é e como vive. Belo Horizonte: Editora UFMG, 2009.

THEODORO, Mário. As características do mercado de trabalho e as origens do informal no Brasil. In: Jaccoud, Luciana (org.) Questão social e políticas sociais no Brasil contemporâneo. Brasília: IPEA, 2005. p.91-126.

Recebido em 03/08/2019.

Aprovado em 21/08/2020. 